\title{
The Importance of Common Grazing Lands for the Sustainable Management of Natura 2000 Areas in Bulgaria
}

\author{
Yanka KAZAKOVA-MATEVA ${ }^{1^{*}}$ \\ ${ }^{1}$ European Forum on Nature Conservation and Pastoralism/ Department of Natural Resources \\ Economics, University of National and World Economy, Bulgaria \\ *)Corresponding author, e-mail: yanka.kazakova@gmail.com
}

BulletinUASVM Horticulture 73(1) / 2016

Print ISSN 1843-5254, Electronic ISSN 1843-5394

DOI:10.15835/buasvmcn-hort:11816

\begin{abstract}
Common grazing is a traditional practice in Bulgaria. After land restitution in the post-socialist land reform, common grasslands are owned by municipalities or the state and are rented out for grazing to livestock breeders. The introduction of EU CAP area-based payments have led to a series of legal changes in common land regulations so that they are made eligible for support. At the same time, the EU nature conservation legislation requires that Natura 2000 zones are designated in a way that protects all species and habitats of European importance. Due to the historically low-intensity farming practices, it is estimated that the majority of grasslands in Natura 2000 areas in Bulgaria are common grasslands. This paper aims to analyse the available data about regional distribution of common grasslands and to assess their importance for the sustainable management of Natura 2000 zones based on their eligibility for CAP direct payments. The method used is data analysis and GIS spatial representation of both municipal and state common grasslands in Natura 2000 zones across the 28 administrative districts in Bulgaria. Based on the findings of this research work, we demonstrated that common grasslands have an important share in the territorial scope of Natura 2000 sites and can provide substantial financial support for ensuring their sustainable management.
\end{abstract}

Keywords: common land, GIS, grazing, Natura 2000, sustainable management

\section{INTRODUCTION}

The theory of governance and management of commons has been developing extensively since 1968 when Hardin's "Tragedy of the commons" has been first published. It provided a rather negative view on the potential for sustainable management of common resources. It took more than 20 year until another, equally strong in opinion and justification study was published - "Governing the Commons" by Elinor Ostrom (1990), and scientific studies and discussions became more balanced and positive on the future role of commonly managed resources in sustainable development. Ostrom (1999) defined a set of design principles that characterize all of the robust commons institutions. By „design principle“ she meant an essential element or condition that helped to account for the success of these institutions in sustaining the commons and gaining the compliance of generation after generation of participants to the rules-in-use. Ostrom's design principles include clearly defined boundaries, congruence between rules and local conditions, collective choice arrangements, monitoring and graduated sanctions, conflict resolution mechanisms, minimal recognition of the rights to organize as well as nested enterprises. In addition, in her further research (1999) she recognized that even if all design principles are met, failures still happen, on which basis she also identified eight key threats to sustainable institutions such as blueprint thinking, overreliance on simple voting rights, rapid exogenous changes, transmission failures, turning to external sources 
of help too frequently, international aid that ignores indigenous knowledge and institutions, corruption and other forms of opportunistic behavior and lack of large scale supportive institutions. The more recent academic studies of commons governance reveal an emerging view that rules are subject to constant interpretation, negotiation, reinterpretation and change, and, as a consequence, property rights are rarely static and clear-cut in practice (Brown et al, 2003). Turner (2007) considers commons governance systems from the conservation perspective, which he finds makes the "governance systems even more complicated". One aspect that he addresses is the varying goals that the different stakeholders such as commons users, local governments and conservationists may have, for example, equitable distribution to group members of the benefits of the resource; economically profitable utilization, widespread participation by group members, conservation and/or preservation of the natural resource. Another important aspect of the commons governance systems in Europe is making these systems fit to the requirements of the Common Agricultural Policy of the EU while at the same time ensuring the nature conservation values of the pastures' natural resource (Jones 2012, Short 2008, Short \& Waldon 2013, Baur \& Binder, Sutcliffe at al. 2011, Kazakova \& Stefanova 2011).

Common grazing is a traditional practice in Bulgaria. Historically, each village or municipality owned and used commonly forests, mountain pastures and villages "meri" where livestock grazed in summer months. The total number of livestock depended on the number, size and quality of the village grasslands. Each type of animals had a special zone for grazing. For example, goats and non-milking sheep were on the highest mountain pastures. Horses, cows and calves grazed the lower pastures. Milking sheep grazed in the lower and warmer areas. This practice was altered by the collective agricultural cooperatives during socialism.

After land restitution in the post-socialist land reform, common grasslands are owned by municipalities or the state and are rented out for grazing to livestock breeders. Common grazing or common land use is specifically defined in the Act on ownership and use of agricultural land (AOUAL) as "traditional practice of the inhabitants of the settlement with small livestock farms grazing on public "meri" and pastures, including by forming one or more "collective" (common) herds for grazing" (para.2(d) of the additional provisions). Prior to Bulgaria's accession to the EU, the use of common land followed the historical tradition in the village and/or was informally agreed between the livestock owners in the different village herds.

The introduction of the CAP support measures and direct payments in 2007 made it evident that the existing legislative framework needed amendment. The users of the common lands (whether collective (association) or individual) needed to have a legal right to use the grasslands in order to be eligible for CAP area-based payments. The use of the common grasslands had to become regulated in a written form and agreed by the municipal assembly. Additionally, a rule to maintain the grasslands in good agriculture and environmental conditions was introduced. These two changes were about to bring another series of significant changes in the use of common grasslands for the last decades. First, the collective herds had to register as associations if they wanted to receive CAP support on the grazed lands; alternatively, the livestock owners had to apply for individual use of grasslands. Second, common grasslands were classified in three categories: (1) Permanently ineligible for SAPS support -areas in permanent pastures covered by trees or shrubs, buildings, facilities, rocks, stones, eroded or bare lands. (2) Pastures, partially ineligible for support, when parts of them are covered by trees or shrubs, buildings, facilities, rocks, stones, eroded or bare lands, compactly situated and covering individually or together more than 100 sq.m. (3) Permanent pastures eligible for support: they are used for livestock grazing or mowing, and have not more than 50 trees and/or shrubs mosaic situated; and trees and/or shrubs density allows free grazing of animals; and/or have mosaic-like situated buildings, facilities, rocks, stones, eroded or bare lands covering not more than $10 \%$ of the pasture's total area. In the years that followed, especially 2008 and 2009, there were regular complains and court cases from livestock farmers about penalties imposed due to ineligible land used for grazing, however no official data was available.

During the same period, the zones of the European ecological network of protected areas (Natura 2000 zones) were designated covering 
around $33 \%$ of the country's territory. The Specially Protected Areas (SPAs) under the Birds Directive are 118 and the proposed Sites of Community Importance (pSCIs) under the Habitats Directive are 234. There are a total of 90 habitat types of European importance in Bulgaria, and 18 of them are natural and semi-natural grasslands. The assessment of the ecosystems (PAF, 2014) reveals that $13.47 \%$ of the Natura 2000 territories are covered by grasslands ecosystems. Due to the historically low-intensity farming practices for common grazing, it is estimated that the majority of grasslands in Natura 2000 areas in Bulgaria are common grasslands.

This paper aims to analyse the recently published data (MAF, 2015) about permanent pastures in Bulgaria from the perspective of (1) regional distribution of common grasslands and (2) to assess their importance for the sustainable management of Natura 2000 zones based on their eligibility for CAP direct payments.

\section{MATERIALS AND METHODS}

The method used is data analysis and GIS spatial representation of both municipal and state common grasslands in Natura 2000 zones across the 28 administrative districts in Bulgaria. The GIS software used for the analysis and spatial representation is MapInfo Professional 12.0. It is a fact-finding analysis of the status of municipal and state grasslands in one year (2015) since there is no previous geo-referenced data available. The Bulgarian Ministry of Agriculture published for the first time in 2015 the areas classified as permanent pastures according to the requirements of the new CAP support 2014-2020. This is a sub-sets of the overall Land Parcel Identification System (LPIS), which was established and is updated annually for the administration and management of the CAP payments. The permanent pastures data is georeferenced and provided at administrative districts level (NUTS III). Within the district dataset, data is disaggregated at municipal (LAU 1), settlements (LAU2) and parcels levels. Land ownership and land use are also defined as well as the parcel's eligibility for CAP support and whether it is in SPAs or pSCIs boundaries.

The first stage of the analysis related to processing the newly available data and involved 28 individual datasets. If they remained separate, that would have involved too many unnecessary repetitions and would have made the comparison between the districts more difficult. Thus, the first step was to select only the permanent pastures, which were in municipal or state ownership. This reduced the size of each of the 28 datasets and allowed joining them in one dataset. In the second step, the municipal and state grasslands in the SPAs and pSCIs were selected and their eligibility for CAP support was assessed. Since many SPAs and pSCI have overlapping territories, the third step was to analyse the scope and eligibility of the grasslands, which are both SPA and pSCI (overlapping Natura 2000 common grasslands). The fourth step involved analysis of the scope and eligibility of all grasslands in Natura 2000 zones, whether SPAs or pSCIs, excluding the double counting of overlapping territories (all Natura 2000 common grasslands). The last step was to overlay all Natura 2000 common grasslands with a layer of mountain settlements.

The second stage of the analysis was to estimate the potential financial support for farmers managing grasslands in Natura 2000 areas through the area-based measures of the Bulgarian Rural Development Programme 20142020. The two relevant measures were measure 12.1 "Compensation payments to Natura 2000 agricultural areas", which is implemented in Natura 2000 are for the protection of wild birds (SPAs) and measure 10.1. "Payments for commitments related to agri-environment-climate for the restoration and maintenance of grasslands of high nature value", which is implemented in Natura 2000 areas for the conservation of habitats (pSCI).

\section{RESULTS AND DISCUSSION}

The first result of the assessment of the newly published LPIS data, maintained by the Ministry of Agriculture, relates to the total coverage of permanent pastures in Bulgaria in 2015. It includes all pastures, meadows and meri (areas near settlements traditionally used for grazing) under private, public, collective, church or other ownership. The total area of permanent pastures in LPIS is calculated at 881895 ha. At the same time, the National Statistical Institute reports 1363984 ha of permanent grasslands in 2015. There is a "loss" of almost half a million hectares in LPIS - a data mismatch that was discussed previously (Kazakova, 2012). Thus, it is important to underline that the analysis in this paper focuses 
only on the data contained in the LPIS sub-set on permanent pastures in 2015 as published by the Ministry of Agriculture.

The total area of state-owned and municipal pastures in Bulgaria in 2015 is 541368 ha (Fig.1). These public pastures traditionally are considered common pastures, due to the historical practice of common grazing. In 2009, the rights for the management of state pastures and "meri" were transferred to the municipalities (Art.37(i) - art.37(r), AOUAL/2009) when and if the municipalities wanted to manage them. Since then, the responsibility for the management of this land resource lies with the municipal assembly and municipal mayor under the supervision of the district governor (representing the state interest). Although common grasslands are distributed throughout the country, not all municipalities or districts have comparable pastures stocks. Blagoevgrad is the district which considerably outnumbers all other districts with 68566 ha of common grasslands. The next one is Sofia district which has 37441 ha. At the bottom is Sofia-city with as little as 842 ha. In the low end are also Turgovishte and Gabrovo districts with 3 040ha and 4563 ha respectively.
An important aspect of the availability of common grasslands is their eligibility for CAP support (Fig.1). Since the legal changes in 2007, when written contracts had to be issued for the use of common grasslands, most of them were in individual use as opposed to the common grazing before. For example, in Godech municipality (Sofia district) there are 6999 ha of municipal pastures. According to their annual grazing plan (2015), only 149 ha are allocated for common grazing (STEP, 2015). The majority of the rest are under contracts for individual use by livestock owners or land managers, both of whom apply for CAP funding.

Since 2012, the Ministry of Agriculture created a specialized layer in the LPIS "Areas eligible for support", which included the areas in good agriculture condition assessed at the level of physical block. It is renewed annually and aims to make the process easier for both the administration and the farmers (Ordinance 105, MAF). Thus, in 2015 , the share of municipal and state grasslands eligible for support at national level is $71 \%$ or 386169 ha. At district level, the share of eligible grasslands is highest in Dobrich, Plovdiv and Sofia districts (81\%), Pleven (80\%) and Silistra (79\%).

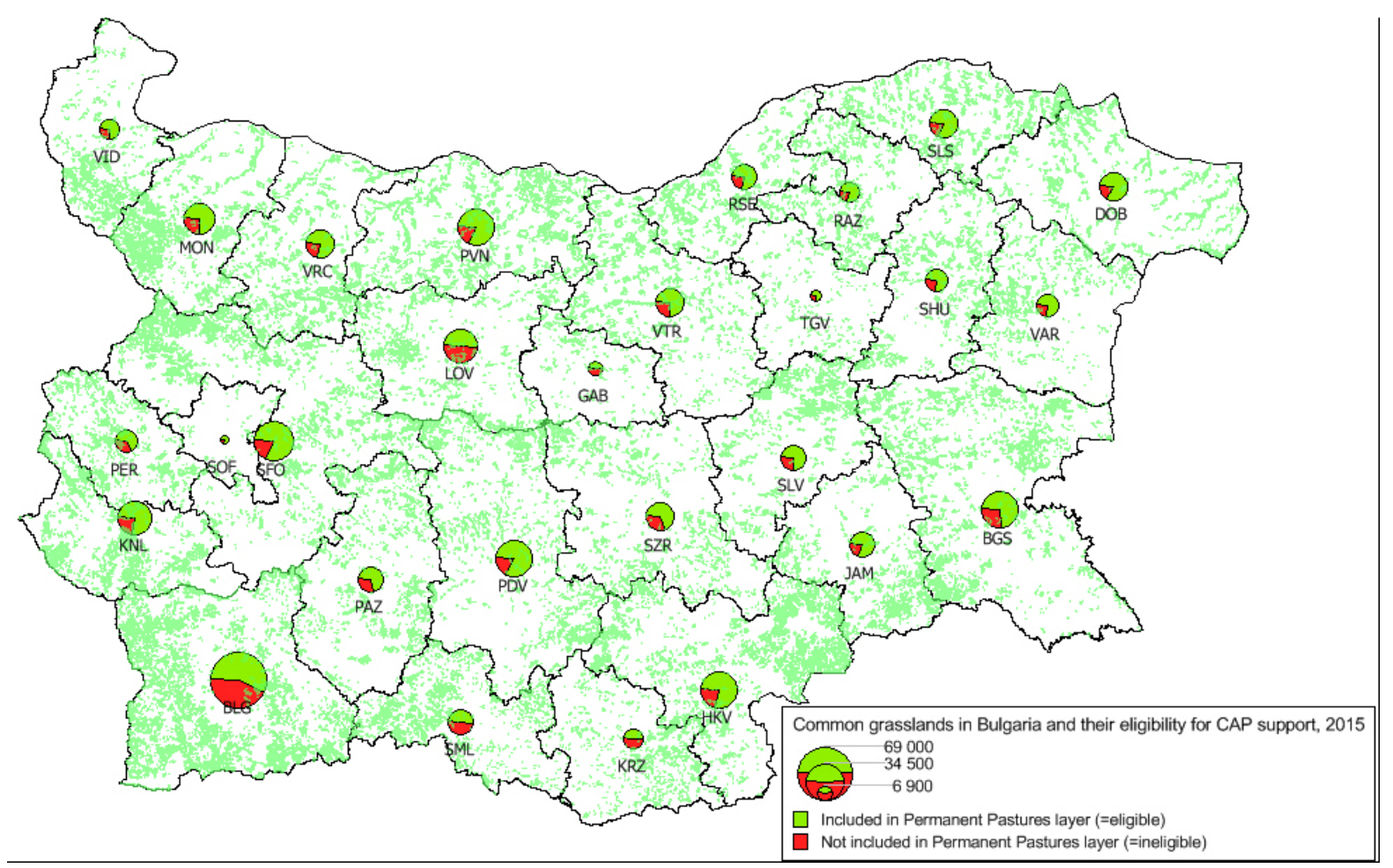

Fig. 1 Common (municipal and state-owned) grasslands in Bulgaria and their eligibility for CAP support in 2015, Data source: MAF LPIS data, Author's processing. 
The share of ineligible grasslands is highest in Kurdzali (48\%), Lovech, Smolyan and Gabrovo (all at $47 \%$ ) and Blagoevgrad (42\%). It is observed that the share of grasslands eligibility/ineligibility is not related to the size of the available stock. Blagoevgrad district has the highest stock of common grasslands and $42 \%$ of them are not eligible for support. Gabrovo, on the other hand, is one of the districts with lowest grasslands stock and still $47 \%$ are not eligible for support. All five districts with high share of ineligible grasslands have also large shares of mountainous and semi-mountainous areas. This finding requires additional studies to see if there are relationships between grasslands eligibility and mountainous areas.

\section{Natura 2000 and grasslands}

The National Natura 2000 Priority Action Framework states that $94 \%$ of the grasslands habitats in Natura 2000 are in unfavourableunsatisfactory condition (MoEW, 2014). Only two other habitat groups are in worse condition - the coastal sand dunes and the freshwater habitats are $100 \%$ in unfavourable-unsatisfactory conditions. This motivated the assessment of the role and importance of common grasslands to the management of Natura 2000 sites.
In the period when Natura 2000 sites were designated - prior to EU accession in 2007, the majority of common grasslands were still used for common grazing with agreed allocation of areas for cattle, sheep and goats grazing. Since 2007, when the individual contracts for the use of common grassland spread, the main criteria for allocating the grasslands is their eligibility for CAP support. Natura 2000 network is comprised of two groups of sites: 1) for the preservation wild birds - SPAs under the Bird Directive; and 2) for the conservation of natural habitats - SCIs under the Habitats Directive. The SPAs in Bulgaria already have legal orders for their designation and management, while the SCIs still expect the orders to be officially published. This means that they have no official land use restrictions yet.

There are 119 SPAs in Bulgaria covering 2578 $000 \mathrm{ha}$. The data analysis performed for this study, reveal that the total area of common grassland in Natura 2000 areas for the protection of wild birds (SPAs) is 234928 ha or $43 \%$ of all common grasslands in the country (Fig.2); of them 74\% are eligible for support. This is a higher eligibility share as compared to the total common grasslands eligibility. According to the LPIS dataset, common grasslands cover $9.11 \%$ of the total SPAs territory.

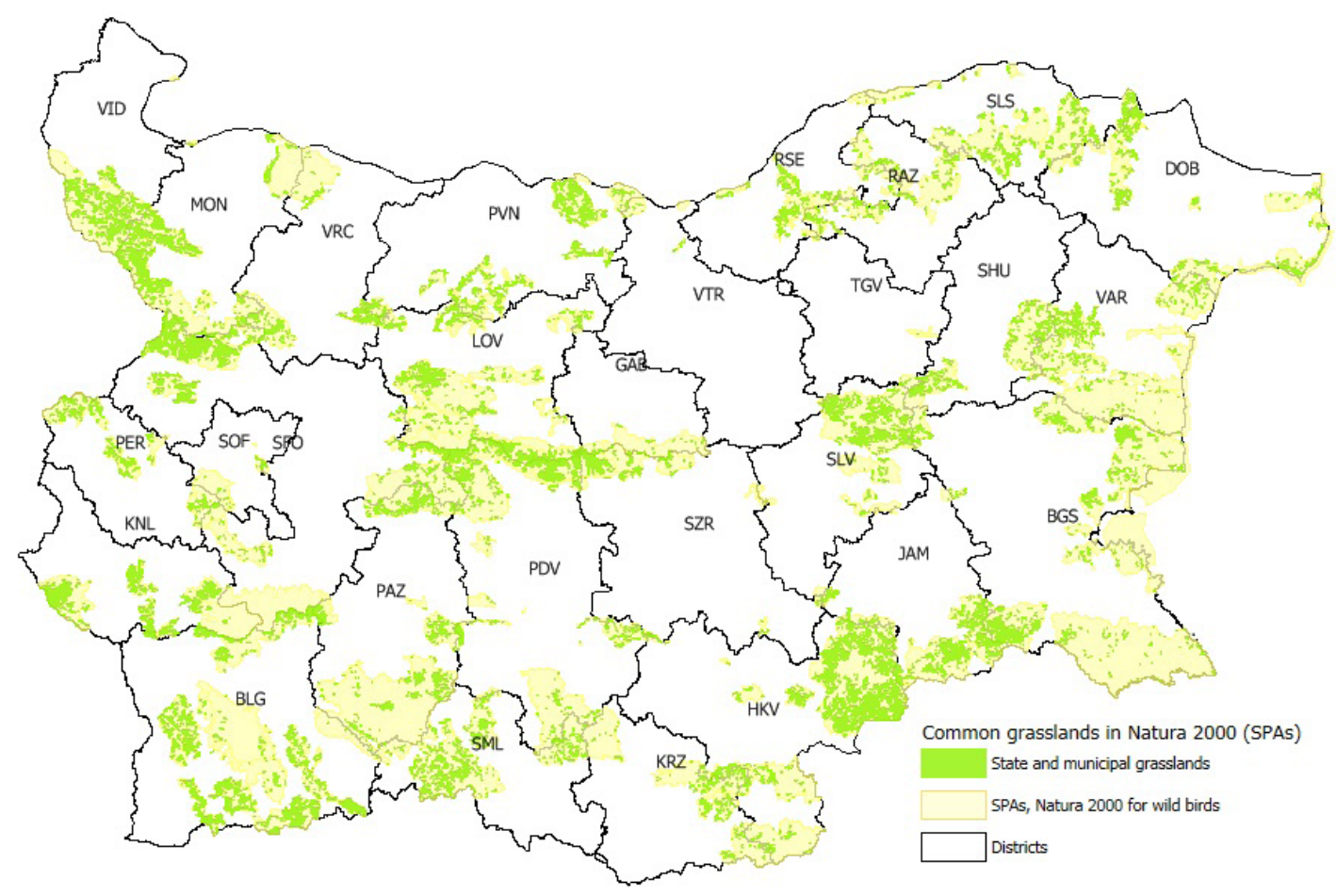

Fig.2. State and municipal grasslands in SPAs (Natura 2000 zones under the Birds Directive). Data source: MAF LPIS data on grasslands; MoEW data on Natura 2000 boundaries. 
Overlaying the LPIS common grasslands in SPAs layer with the layer of the SPAs boundaries, maintained by the Ministry of Environment and Water reveals full compliance between the two datasets. This is important, because the agricultural lands, including grasslands, in SPAs are subject to compensation payments for restrictions arising from the Natura 2000 designation orders under measure 12.1 of the Bulgarian Rural Development Programme 2014-2020. Any mismatch between the two datasets would mean incorrect implementation of the measure, either at the expense of the European taxpayer or to the farmers in Natura 2000 zones. At the same time, Fig. 2 shows all common grasslands in the SPAs, including the $26 \%$ that are ineligible for support.

The Natura 2000 areas under the Habitats Directive (pSCIs) in Bulgaria are 233, covering 3574 100ha. The analysis of LPIS data shows that the common grasslands in them are 321001 ha, covering $8.98 \%$ of their territory (Fig.3). The common grasslands in pSCIs represent 59.3\% of all common grasslands in the country. Their eligibility share for CAP support is higher - at 78\%.

Two other aspects are key when analysing the importance of common grasslands for Natura 2000 management in Bulgaria. The first one is the overlapping territories between the SPAs and pSCIs. Theoretically, these are the territories with highest concentration of valuable biodiversity for flora and fauna species. Therefore, the sustainable management of these territories should be of highest importance for nature conservation. The common grasslands in overlapping Natura 2000 areas cover 221079 ha, which is $40 \%$ of all common grasslands in the country (Fig.4). This very high share requires targeted attention by municipal authorities to regulate and manage the use of these grasslands and their highest nature value. At the same time, the eligibility of these common grasslands falls to $69.6 \%$. A linear thinking implies that higher nature values most likely leads to lower grasslands eligibility for CAP support but this requires further studies and analysis. It also implies that the areas of most need of compensation for Natura 2000 management restrictions are most likely not going to be able to claim it due to grasslands' ineligibility for CAP support.

The second key aspect is the overall area of common grasslands in Natura 2000 areas irrespective of SPAs or pSCIs. These common grasslands are 372546 ha, or $69 \%$ of all common grasslands (Fig.5). Their eligibility is $72 \%$, which

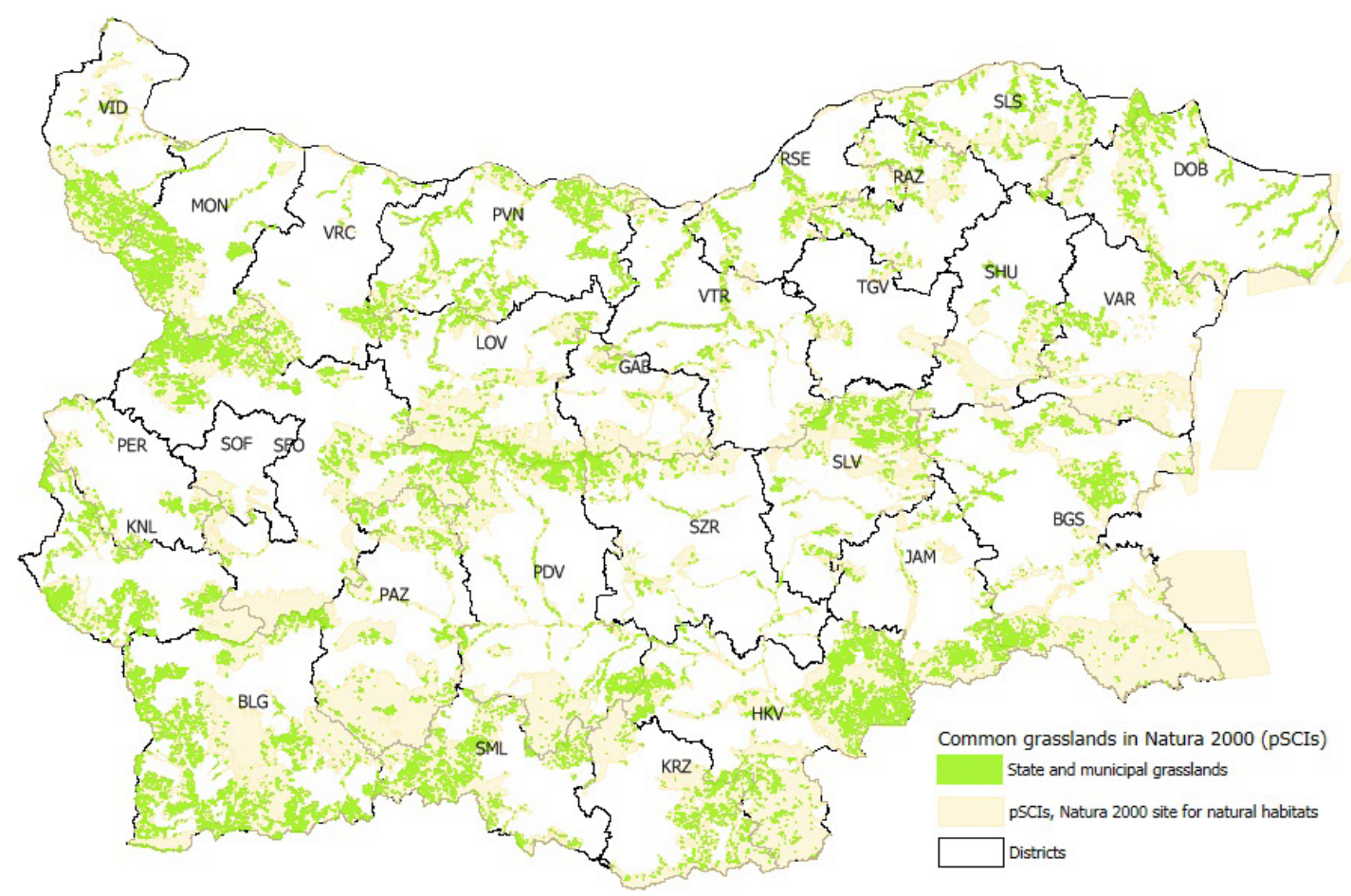

Fig.3 State and municipal grasslands in pSCIs (Natura 2000 zones under the Habitats Directive). Data source: MAF LPIS data on grasslands; MoEW data on Natura 2000 boundaries. 


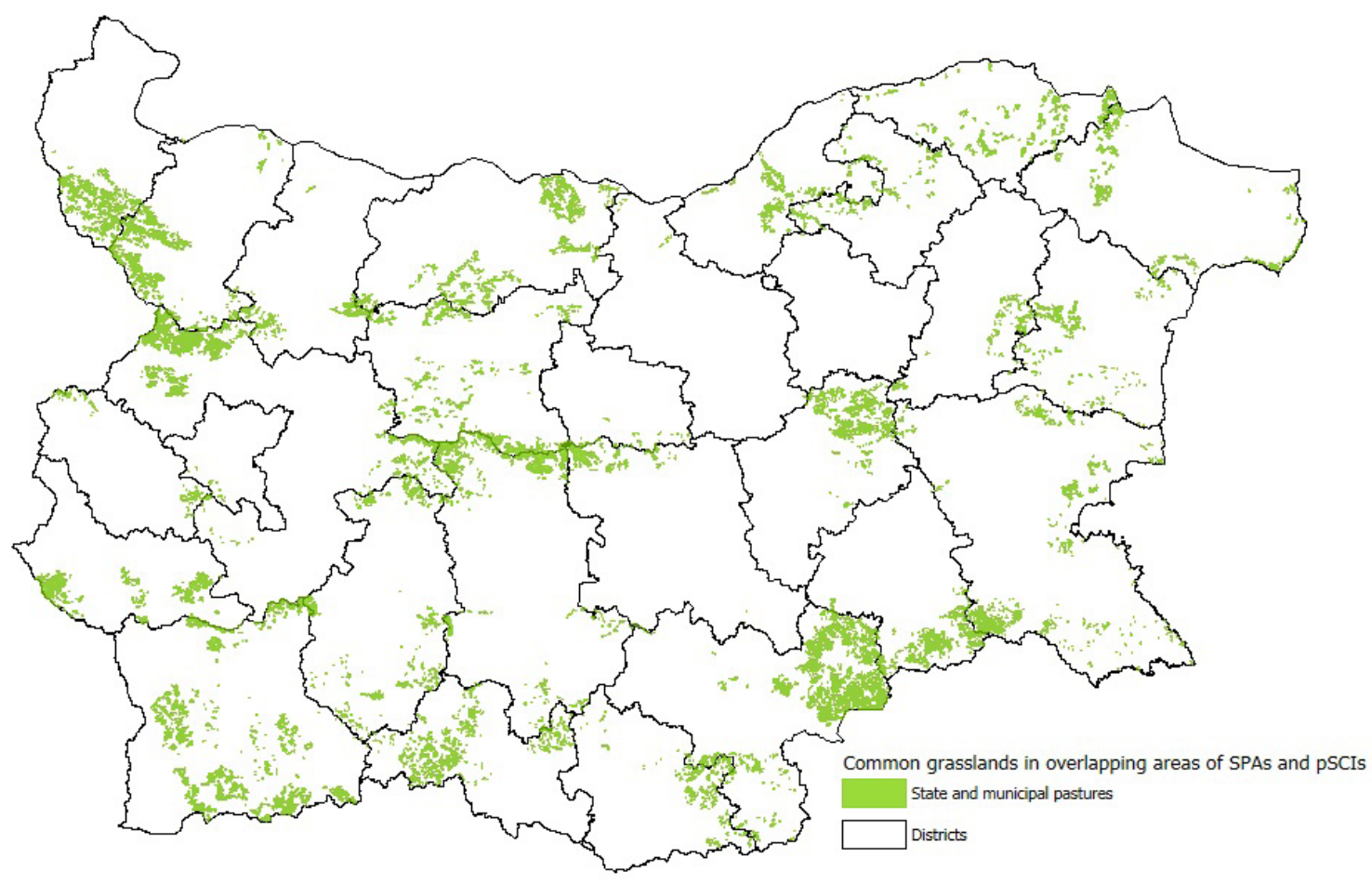

Fig.4 State and municipal grasslands in overlapping areas of SPAs and pSCIs (Natura 2000 zones under the Birds and Habitats Directives). Data source: MAF LPIS data on grasslands.

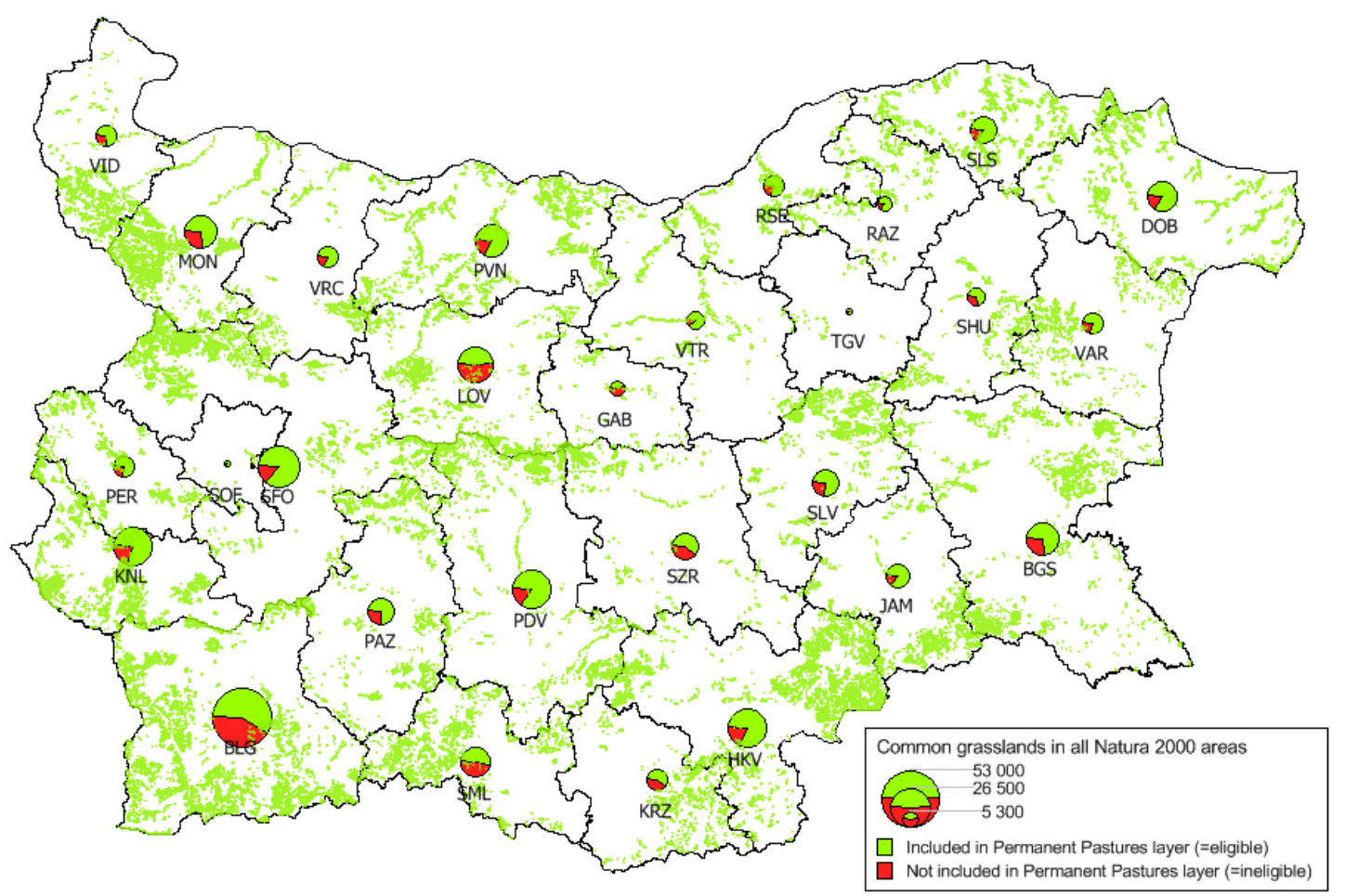

Fig.5 Total state and municipal grasslands in either SPAs or pSCIs (Natura 2000 zones under the Birds and Habitats Directives) and their eligibility for CAP support in 2015. Data source: MAF LPIS data on grasslands. 
is very close to the average for all common grasslands (71\%). However, the regional (districtlevel) eligibility has changed. There are 12 districts where the eligibility of common grasslands in Natura 2000 areas is above $80 \%$. These are Veliko Turnovo (86\%), Sofia (85\%), Jambol and Sofiacity (84\%), Plovdiv (83\%), Silistra, Dobrich and Razgrad (82\%), Turgovishte, Vraca and Pleven (81\%) and Haskovo (80\%). Gabrovo is the district with worst eligibility status with only $47 \%$ of Natura 2000 common grasslands eligible for support. In the lower end are also the districts of Lovech (51\%), Smolyan (55\%) and Blagoevgrad (59\%). They were also the districts in the lower end of eligibility of all common grasslands. The need for further assessment of the relationship between common grasslands in mountains and land eligibility for CAP support is thus, restated.

\section{Common grasslands in Natura 2000 areas and CAP support}

The common grasslands in SPAs, which have official designation orders, are subject to support from measure 12.1 "Compensation payments to Natura 2000 agricultural areas". The grasslands in the pSCIs, which still have no designation orders can be supported under measure 10.1. "Payments for commitments related to agri-environmentclimate for the restoration and maintenance of grasslands of high nature value".

Measure 12.1 "Compensation payments to Natura 2000 agricultural areas" provides support to farmers to protect, maintain and restore the favourable conservation status of the habitats of flora and fauna species of European conservation importance. The support levels are calculated to each site on the basis of the land use restrictions imposed by the designation orders. The lowest payment for permanent pastures is 16 Euro/ha/ year meaning that there is only one restriction on the use of grasslands. The highest payment is 108 Euro/ha/year, which covers several restrictions such as late mowing, no use of artificial fertilizers, mowing from the center to the end of the grassland parcel, etc. The estimation for the total potentially available "budget" for the sustainable management of grasslands in SPAs is calculated using an average figure for the compensatory payment of 49 Euro/ ha/year (tab.1). This payment is provided to all lands in SPAs, irrespective of their eligibility/ ineligibility for the CAP direct payment scheme the common grasslands in SPAs are 234928 ha. On the other hand, the payment under the Single Area Payments Scheme (SAPS), Pillar I of CAP, is provided only to areas in the eligible layer. The SAPS payment in 2015 is 85 Euro/ha, and the common grasslands in SPAs eligible for it are 173440 ha. Thus, the total budget potentially available for the sustainable management of common grasslands in SPAs sums up to 26253872 Euro, comprised of 11511472 Euro under Measure 12.1. and 14742400 Euro under the SAPS scheme.

Measure 10.1. "Payments for commitments related to agri-environment-climate for the restoration and maintenance of grasslands of high nature value" is provided to all grasslands of High Nature Value in the country. The areas in pSCIs are able to benefit from it until they get the designation orders officially published. After that, they will receive support from measure 12.1. At the same time, the overlapping areas in pSCIs, which are also SPAs, are only eligible for support under measure 12.1. Therefore, for the estimation of the potential budget for sustainable management of common grasslands in pSCI, only the areas outside SPAs are used (tab.2). The agri-environmental payment is calculated at national level and equals 126.80 Euro/ha for grazing areas of High Nature Value. The total potential budget in pSCIs only equals 20871080 Euro. It is comprised of 12670110 Euro from measure 10.1. Agri-environment and climate, and 8200970 Euro from SAPS scheme.

The overall potential annual budget for the management of common grasslands in Natura 2000 areas (both SPAs and pSCIs) in Bulgaria can

Tab 1. Estimation of potential annual "budget" for common grasslands in SPAs

\begin{tabular}{cccc}
\hline Measure/scheme & $\begin{array}{c}\text { Area subject to support } \\
\text { (ha) }\end{array}$ & $\begin{array}{c}\text { Payment } \\
\text { (Euro/ha) }\end{array}$ & $\begin{array}{c}\text { Total } \\
\text { (Euro) }\end{array}$ \\
\hline Measure 12.1. & 234928 & 49 & 11511472 \\
\hline SAPS scheme & 173440 & 85 & 14742400 \\
\hline Total & & & 26253872 \\
\hline
\end{tabular}


reach 47124952 Euro, if all areas were declared for the available support. In reality, a 100\% uptake is not likely to happen. However, the amount in significant, considering that it is related to around $9 \%$ of the territory of Natura 2000 areas in the country. It is even more significant when compared to the total 7-year budget for priority 3 "Natura 2000 and biodiversity conservation" under Operation Programme for Environment 20142020, which is 86181500 Euro. Environmental authorities should place more efforts and attention to the design and implementation of the CAP support schemes in Natura 2000 areas in order to improve the "unfavourable-unsatisfactory" status of $94 \%$ of the grasslands habitats.

\section{CONCLUSION}

The Bulgarian Ministry of Agriculture published for the first time in 2015 sub-sets of the LPIS related to permanent pastures. It contains detailed information about the distribution, land ownership, land use, Natura 2000 protection as well as eligibility for CAP support. This welcomed transparency motivated the fact-finding study presented in the paper. Several important aspects were identified, that require further research:

Common grasslands are distributed throughout the country and represent $61 \%$ of all grasslands in LPIS in 2015. Certain administrative districts have more stock of them - Blagoevgrad has the highest area of common grasslands, while Sofia-city district has the lowest. An important aspect after the EU accession is their eligibility for CAP support. On average it is $71 \%$ and decreases to just above $50 \%$ in several mountainous districts. This relationship requires further studies to assess whether it is due to the mountainous terrain, the type of grasslands, or the lack of or reduced grazing activities in these areas.

Common grasslands cover $9.11 \%$ and $8.98 \%$ of the territories of SPAs and pSCIs, respectively. Having in mind that the grasslands ecosystems cover $13.47 \%$ of the Natura 2000 areas, the sustainablemanagementofcommongrasslandshas a significant role for the achievement of favourable conservation status. In $2014,94 \%$ of the grassland habitats are in unfavourable-unsatisfactory status. Additional research is necessary to understand the influence of the changed management regime of common grasslands after EU accession. In this period, individual contracts became the new "normal" and the common grazing of village herds and flocks began to disappear. It is possible that the management under individual contracts became more intensive with the intension to make more grasslands eligible for CAP SAPS scheme.

Another aspect related to the High Nature Value of common grasslands and their eligibility for CAP support, was uncovered in the assessment of the overlapping SPAs and pSCIs. The common grasslands in overlapping Natura 2000 areas had lower eligibility share $-69 \%$. When compared to $71 \%$ of all common grasslands, $74 \%$ in SPAs only and $78 \%$ in pSCIs only, it raises the question if the areas of concentrated nature value mean lower eligibility for CAP support. Extended further, this questions if the implementation rules for CAP support enable an effective integration of EU nature conservation and agricultural policies or introduces new obstacles.

Last, but not least, the estimated overall potential annual budget from CAP payments to common grasslands in Natura 2000 areas (both SPAs and pSCIs) in Bulgaria can reach 47124952 Euro. This is more than $50 \%$ of the total available 7-year budget under the targeted priority for Natura 2000 management under Operational Programme for Environment 2014-2020. If used wisely, this "budget" can have a positive contribution to improving the conservation status of the grasslands habitats, $94 \%$ of which are currently in unfavourable-unsatisfactory conditions. At the same time, this same "budget" can be a serious trigger to intensified use of

Tab 2. Estimation of potential annual "budget" for common grasslands in pSCIs

\begin{tabular}{ccccc}
\hline Measure/scheme & $\begin{array}{c}\text { Common grasslands } \\
\text { in pSCIs (ha) }\end{array}$ & $\begin{array}{c}\text { Area subject to support: } \\
\text { overlapping excluded (ha) }\end{array}$ & $\begin{array}{c}\text { Payment } \\
\text { (Euro/ha) }\end{array}$ & $\begin{array}{c}\text { Total } \\
\text { (Euro) }\end{array}$ \\
\hline Measure 10.1. & 321001 & 99922 & 126,80 & 12670110 \\
\hline SAPS scheme & 250267 & 96482 & 85 & 8200970 \\
\hline Total & & & & 20871080 \\
\hline
\end{tabular}


common grasslands that would lead to further degradation of their conservation status.

Therefore, the importance of common grasslands for the sustainable management of Natura 2000 sites is significant. Even more, it is a key performance indicator for nature conservation and agricultural policy and practice integration at local (municipal), national and European level.

Acknowledgements. This paper was developed in the framework of the DG Environment NGO Operating Grant 2015 to the European Forum on Nature Conservation and Pastoralism, in partnership with the project "Nature-friendly management of pastures" (2014-2015) implemented by the Society for Territorial and Environmental Prosperity (Bulgaria) and funded by the EEA NGO grants.

\section{REFERENCES}

1. Baur I, Binder CR, (undated) Adapting to Societal Transitions by changing Rules in the Governance of Common Property Pastures in the Swiss Alps, Ecology and Society Journal, http://dlc.dlib.indiana.edu/dlc

2. Brown KM (2003). New Challenges for Old Commons: the implications of rural change for crofting common grazings, Landscape, Law \& Justice: Proceedings from a workshop on old and new commons, Centre for Advanced Study, Oslo, 11-13 March 2003

3. Hardin G (1968). The Tragedy of the Commons, Science Magazine, New Series, Vol. 162, No. 3859 (Dec. 13, 1968), pp. $1243-1248$

4. Jones G (2012). Supporting Common Grazing through Agri-environment - lessons from an ex post evaluation, A Report for the European Forum on Nature Conservation and Pastoralism (EFNCP) http://efncp.org/download/ SRDP-CG-report.pdf

5. Kazakova Y (2012). Lies, damned lies and statistics, La Cañada - Newsletter of the European Forum on Nature Conservation and Pastoralism, Number 2, p.13-14, Winter 2012, ISSN 1027-2070, http://www.efncp.org/ download/la-canada29.pdf

6. Kazakova Y, Stefanova V (2011). Common Grazing Land in Bulgaria: Overview of Current Status and Management Challenges. Conference paper in "Shared Resources in a Rapidly Changing World", European Conference of the
Intl Association for the Study of the Commons, Plovdiv, https://dlc.dlib.indiana.edu/dlc/handle/10535/7693

7. Ministry of Agriculture and Food, Ordinance 105 regulating the process and procedure of creation, maintenance, access and use of the Integrated Administration and Control System, adopted on 22 August 2006, updated in 2006, 2007, 2008, 2011, 2012, 2014 and 2015

8. Ministry of Agriculture, Act on ownership and use of agricultural land (AOUAL), adopted on 1 March 1991, amended in 1992, 1993, 1994, 1995, 1996, 1997, 1998, 1999, 2000, 2002, 2003, 2004, 2005, 2006, 2007, 2008, 2009, 2010, 2011, 2012, 2013, 2014, 2015

9. Ministry of Agriculture and Food (2015) Permanent Pastures Eligible for Support, Accessed at ftp://212.122.182.203/

10. Ministry of Environment and Waters (2014) National Natura 2000 Priority Action Framework (PAF) for the 2014-2020 financial period, final version, April 2014, Sofia, Accessed at http://www.moew.government. bg/?show=top\&cid=568

11. Ministry of Environment and Waters (2015) Natura 2000 Information System, Accessed at http://natura2000. moew.government.bg/Home/Documents

12. Ostrom E (1990). Governing the Commons. The Evolution of Institutions for Collective Action, Cambridge: Cambridge University Press, pp. 280

13. Ostrom E (1999). Design Principles and Threats to Sustainable Organizations That Manage Commons, a paper for Workshop in Political Theory and Policy Analysis, Indiana University

14. Short C (2008). The traditional commons of England and Wales in the twenty-first century: meeting new and old challenges, International Journal of the Commons, Vol.2/2, pp. 192-221

15. Short C, Waldon J (2013). The apportionment of agrienvironment schemes monies on common land in England. Report to the European Forum for Nature Conservation and Pastoralism. Foundation for Common Land: Penrith

16. http://efncp.org/download/aescommonsfclresearchreport23nov13final.pdf

17. Sutcliffe L, Page N, Leuschner C, Marggraf R (2011). Past, present and future of common grazing land in Romania, a paper presented at the IASC Conference in Plovdiv, September 2011

18. Turner M (2007). Ecological Complexity and the Management of Common Property Resources, Tenure Brief No.5, 2007, Land Tenure Center, University of Wisconsin-Madison. 